\title{
Rafael Diaz-Salazar, Democracia laica y religion publica
}

Madrid, Taurus, 2007, 2006 p.

\section{Michael Löwy}

\section{(2) OpenEdition}

\section{Journals}

Édition électronique

URL : http://journals.openedition.org/assr/22081

DOI : $10.4000 /$ assr.22081

ISSN : $1777-5825$

\section{Éditeur}

Éditions de l'EHESS

\section{Édition imprimée}

Date de publication : 31 décembre 2010

Pagination : 9-242

ISBN : 9782713223013

ISSN : 0335-5985

\section{Référence électronique}

Michael Löwy, «Rafael Diaz-Salazar, Democracia laica y religion publica », Archives de sciences sociales des religions [En ligne], 152 | octobre-décembre 2010, document 152-40, mis en ligne le 12 mai 2011, consulté le 21 septembre 2020. URL : http://journals.openedition.org/assr/22081 ; DOI : https:// doi.org/10.4000/assr.22081

Ce document a été généré automatiquement le 21 septembre 2020

(C) Archives de sciences sociales des religions 


\title{
Rafael Diaz-Salazar, Democracia laica y religion publica
}

Madrid, Taurus, 2007, 2006 p.

\author{
Michael Löwy
}

\section{RÉFÉRENCE}

Rafael Diaz-Salazar, Democracia laica y religion publica, Madrid, Taurus, 2007, 2006 p.

1 Cet ouvrage d'un sociologue et philosophe de Madrid est un apport important, d'un point de vue qui se définit comme chrétien laïc, à l'actuel débat européen sur la place des religions dans l'espace public. Son point de départ est le constat, par un penseur laïc éminent, Jürgen Habermas, que nous sommes entrés, en Europe et dans le monde, dans une époque "post-séculaire ", où les religions sont un fait social public. La religion a cessé, depuis trois décennies au moins, d'être une affaire purement "privée », pour occuper une place éminente dans le débat public. Cette participation des organisations religieuses dans la sphère publique est légitime, à condition qu'elle respecte la laïcité de l'État et l'autonomie du processus législatif démocratique.

Or, rappelle l'auteur, plusieurs forces religieuses, de sensibilité "néo-conservatrice», que ce soit aux États-Unis ou en Europe, veulent imposer à l'État leurs conceptions normatives : c'est le cas de la droite chrétienne protestante aux États-Unis, des papes Jean-Paul II et Benoît XVI, et des épiscopats d'Espagne et d'Italie, qui n'acceptent pas l'autonomie de l'État et veulent imposer leur idée de la «Vérité » contre les décisions démocratiques de la société.

3 L'auteur illustre l'affrontement entre deux conceptions opposées des rapports entre valeurs morales et État démocratique en analysant le débat entre le cardinal Ratzinger et Jürgen Habermas - «le principal intellectuel laïc de l'Occident»; il s'agit non seulement de leur controverse à Munich, en janvier 2004, publiée par la suite, mais de l'ensemble de leurs travaux des dernières années. Pour le Cardinal, adepte d'une métaphysique chrétienne de la vérité, l'enjeu est la défense de la loi naturelle 
chrétienne contre le «relativisme »: d'où l'exigence que l'État reconnaisse comme son fondement les valeurs chrétiennes, c'est-à-dire des vérités qui ne sont pas soumises au consensus démocratique. Le philosophe, résolument "post-métaphysique ", plaide par contre pour une " républicanisme kantien », neutre par rapport aux différentes visions $\mathrm{du}$ monde en conflit, tolérant et pluraliste, fondé sur la commune acceptation de la procédure démocratique. La laïcité de l'État ne signifie pas, selon Habermas, que le croyant doive abandonner ses convictions, ni que la religion doive disparaître de la sphère publique (" privatisation »), mais simplement la reconnaissance d'un système de règles démocratiques.

Dans le dernier chapitre du livre, l'auteur plaide pour un christianisme laïc, qui pourrait contribuer à la promotion d'une culture civique, républicaine et démocratique, une culture de la fraternité. Il cite à ce sujet Jean Baubérot, pour lequel certaines formes de christianisme favorisent "la production sociale de l'altruisme », et Jürgen Habermas, pour lequel le christianisme est une des sources culturelles de la solidarité des citoyens. Il se refère aussi à Alexis de Tocqueville, qui aurait mis en évidence le christianisme democratique et républicain des États-Unis. Mais on peut se demander si cette vision tocquevillienne n'est pas un peu trop idyllique: les tendances fondamentalistes et conservatrices du protestantisme américain, si bien décrites par l'auteur, ne font-elles pas partie de la culture politico-religieuse nord-américaine, depuis le XIXe siècle jusqu'à nos jours?

5 Qui seraient, aujourd'hui, les représentants de ce christianisme laï, républicain et solidaire? À propos de la France, l'auteur cite Jacques Delors, Michel Rocard, Emmanuel Mounier, Simone Weil : cela fait un ensemble un peu trop hétérogène... Plus convaincante est son analyse des affinités électives entre l'altermondialisme et les religions de la libération. Le christianisme de la libération est une religion publique, très présente dans le Forum Social Mondial de Porto Alegre, dont 68,5\% des participants se définissent comme " religieux ».

En conclusion, deux forces se disputent le champ religieux : les néoconservateurs de toutes les confessions, désireux d'imposer leurs normes et leurs valeurs à toute la société, et les partisans de la modernisation religieuse, qui proposent la recréation de traditions spirituelles millénaires à l'intérieur de cultures laïques. L'avenir de la démocratie laïque dans le monde dépend en grande mesure du triomphe ou de l'échec de la modernisation religieuse. 